\title{
ANÁLISE DE CITAÇÕES DOS ARTIGOS DA INTERCOM - REVISTA BRASILEIRA DE CIÊNCIAS DA COMUNICAÇÃO (1985- 2008)
}

\author{
ANÁLISIS DE CITAS DE ARTÍCULOS EN INTERCOM - REVISTA \\ BRASILEIRA DE CIÊNCIAS DA COMUNICAÇÃO (1985-2008)
}

\author{
Ida Regina Chittó Stumpf - irstumpf@ufrgs.br \\ Doutora em Comunicação \\ Professora Titular Programa de Pós-Graduação em Comunicação e Informação, \\ Universidade Federal do Rio Grande do Sul, UFRGS \\ Zuleika de Souza Branco - zu_branco@yahoo.com.br \\ Mestranda do Programa de Pós-Graduação em Comunicação e Informação, \\ Universidade Federal do Rio Grande do Sul, UFRGS
}

\begin{abstract}
Resumo
Estuda a produção científica em Ciências da Comunicação por meio da análise da Intercom - Revista Brasileira de Ciências da Comunicação, a primeira publicada por uma sociedade científica e a mais antiga na área ainda em atividade. Através da técnica bibliométrica de análise de citações, analisam-se os 287 artigos publicados entre 1985 e 2008. Dos documentos citados, estudam-se as seguintes variáveis: autores citados; tipo de autoria; autocitação; tipo de documento; título de periódico; idioma; local de publicação; idade do documento. A análise das 5.801 referências revela que foram citados 3.604 diferentes autores. Entre estes, estão como os mais citados José Marques de Melo, Jesús Martín-Barbero, Armand Mattelart, Pierre Bordieu, Paulo Freire, Guillermo Orozco Gómez, César Ricardo Siqueira Bolaño, Jurgen Habermas, Néstor García Canclini e Sérgio Caparelli. A autocitação ocorre em 137 artigos, totalizando 6\% do total das citações (346 autocitações). Livro e capítulo de livro constam como os tipos de documentos mais citados (70,7\%). Entre os 337 títulos de periódicos arrolados, os 10 com maior percentual de citações são: Comunicação \& Sociedade; Intercom - RBCC; Diálogos de La Comunicación; Comunicación y Cultura; Journal of Communication; Journalism Quarterly; Media, Culture and Society; Critical Studies in Mass Communication; European Journal of Communication; e Telos. O português é o idioma de $53 \%$ das citações, seguido do inglês e do espanhol. A maior parte dos documentos citados $(48,2 \%)$ foi publicada no Brasil. O maior percentual de citações refere-se a
\end{abstract}


documentos publicados antes de 1985, independentemente do ano de publicação do artigo. Diante dos resultados, afirma-se que o estudo revela o comportamento de citação da comunidade científica de Comunicação que publica na Intercom - RBCC.

\section{Palavras-chave}

Bibliometria. Análise de citações. Ciências da Comunicação.

\section{INTRODUÇÃO}

Um dos objetos mais comuns de pesquisa em comunicação científica são as revistas científicas por se constituírem a forma mais usual de divulgar a produção de determinada área do conhecimento. Elas podem ser estudadas de várias formas, tanto em seu conjunto como individualmente, e sua análise é uma das formas de conhecer a trajetória de pesquisa e a dinâmica da comunicação num campo do saber. O estudo realizado selecionou uma revista da área de Comunicação e sobre ela lançou o olhar nas citações dos artigos divulgados entre 1985 e 2008. A escolha de Intercom - Revista Brasileira de Ciências da Comunicação foi feita obedecendo a alguns critérios de representação para a área, como: ser publicada pela primeira sociedade científica - a Sociedade Brasileira de Estudos Interdisciplinares da Comunicação (Intercom) e ser a publicação periódica mais antiga em Comunicação no Brasil, ainda em atividade. Para estudar as citações, aplicou-se o método bibliométrico de análise de citações para identificar o comportamento dos pesquisadores no uso da informação e, também as características dos documentos por eles citados para embasar seus trabalhos.

A análise de citações é uma técnica bibliométrica, considerada como "a área mais importante da bibliometria [...] Investiga as relações entre os documentos citantes e os documentos citados" (ARAÚJO, 2006, p. 18). Esta técnica, portanto, pode ser utilizada nos dois sentidos, podendo contar quantas vezes os documentos são citados e quantas vezes citam outros documentos. Identificar quantas citações um documento ou um autor recebeu pode ser indicativo de quão influente ou quão impactante é ou foi um pesquisador ou determinado conteúdo na comunidade científica da área (SILVA; BIANCHI, 2001).

A técnica é utilizada, também, para a identificação de fontes de informação selecionadas por cientistas e pesquisadores para fundamentar seus estudos, a partir do levantamento de variáveis quantitativas. Os documentos citados por um autor são valiosas fontes de dados para a análise de uso e para mensurar demandas de informação. Estudar as fontes de informação escolhidas por uma comunidade científica permite o mapeamento de características da dinâmica de seus processos de comunicação científica.

A Associação Brasileira de Normas Técnicas (2003, p. 2) define citação como a "menção de uma informação extraída de outra fonte". Assim, a partir da citação, um documento remete a outro, estabelecendo inter-relação entre eles. Para Leite (2001, p. 202) "[...] citar é reproduzir um texto ou uma fórmula de outro autor, geralmente para ilustrar ou sustentar o que se afirma, o que acarreta a 
obrigação, para evitar o plágio, de indicar claramente e sem equívoco a origem da informação". Para o desenvolvimento de suas atividades, o cientista precisa acessar o conhecimento registrado anteriormente, a fim de fundamentar seu trabalho e comparar resultados. Ziman (1979, p. 25) afirma que "[...] todo cientista vê com seus próprios olhos e com os de seus predecessores e colegas". Assim, qualquer trabalho científico fará uso de fontes de informação, gerando uma lista de referências que são apresentadas, em geral, ao final dos trabalhos publicados.

A citação permite identificar outras publicações com temáticas próximas às tratadas pelo documento que as citou. Para Noronha e Ferreira (2003, p. 249), as citações são importantes para "[...] identificar os pesquisadores cujos conceitos, métodos ou teorias serviram de inspiração ou foram utilizados pelo autor no desenvolvimento de seu próprio artigo, estabelecendo-se assim um processo de referência e citação". As mesmas autoras definem citação e referência como duas estruturas com funções diferentes, sendo a referência "o conhecimento que um documento fornece sobre o outro" e a citação, "o reconhecimento que um documento recebe de outro" (p. 249).

Lopes Piñero (1972), por sua vez, diferencia temporalmente citação e referência: citação é o que uma publicação recebe de outra posterior e referência é o que uma publicação faz a outra anterior. Considerando-se que a lista de referências constantes num artigo reflete e representa os documentos utilizados de alguma forma no corpo do texto, para fins deste trabalho, citação e referência são sinônimos, utilizados para referir-se à mesma unidade de análise. Ambas são expressões das fontes de informação utilizadas.

Para Macias-Chapula (1998), a citação é a forma mais comum para se atribuir créditos e reconhecimento na ciência, apesar de nem toda citação expressar concordância com o trabalho citado. Para MacRoberts e MacRoberts (1989), o ato de citar apresenta problemas decorrentes de omissão, tendenciosidade e autocitação, aliados às limitações decorrentes da má elaboração das referências, incompletudes e apresentação de informações errôneas. Estes fatores atrapalham a análise, pois ou se desconhece as razões da citação ou elas remetem a documentos citados incorretamente. No entanto, embora apresente limitações, trata-se de técnica importante na análise da ciência e do uso de informações.

\section{METODOLOGIA}

O estudo buscou conhecer as características dos trabalhos citados por autores que publicaram seus artigos na revista Intercom - RBCC, por meio da análise das citações realizadas nos artigos. As unidades de análise foram os 287 artigos de 46 números da revista, publicados entre 1985 e 2008 e suas 5.801 referências. O período inicial corresponde ao início da publicação de artigos de cunho científico na Revista, nas seções Ensaios; Artigos; Relatos de pesquisa / Comunicações científicas.

Os dados para análise foram extraídos dos artigos publicados na Intercom RBCC e das referências dos artigos, e registrados em planilha eletrônica estruturada no software Excel - Microsoft 2003, contendo as variáveis 
selecionadas como representantes do corpus analisado. Após a coleta inicial, realizou-se levantamento de quantas referências incompletas foram identificadas e quais as variáveis não se encontravam indicadas nas referências. Mediante a constatação do grande volume de referências incompletas ou com dados de identificação incompreensíveis, optou-se por uma segunda pesquisa, realizada em sites da web, por intermédio de buscas por autor e por título dos documentos, com o fim de acrescentar os dados faltantes. Nos casos de variáveis não identificadas, estas foram informadas nos resultados como não identificadas (ni). Estudaram-se as variáveis:

- Autores citados e tipo de autoria - efetivou-se levantamento dos autores citados nos artigos, conforme informados nas referências. Elaborou-se listagem com os autores mais citados. Observou-se o total de autores de cada documento referenciado para a identificação de documentos com autoria única (um só autor) e autoria múltipla (dois ou mais autores) bem como seu reconhecimento como autor pessoal ou institucional. Além disto, observou-se a não indicação de autores, como no caso de entradas pelo título ou do uso da expressão et al., que conforme indica a NBR 6023 / 2002, é utilizada no caso de citações com mais de três autores responsáveis pelo documento citado, impossibilitando conhecer todos os autores da obra referenciada.

- Autocitação - verificou-se a ocorrência da autocitação para identificar artigos nos quais os autores utilizaram como fonte de informação trabalhos de sua autoria, publicados anteriormente. Além da autocitação de autores, observou-se a autocitação da revista, a partir do uso de artigos anteriormente publicados na Intercom - RBCC.

- Tipo de documento - os documentos foram categorizados em 13 grupos: (1) periódicos e artigos de periódicos nacionais; (2) periódicos e artigos de periódicos estrangeiros; (3) livros e capítulos de livros nacionais; (4) livros e capítulos de livros estrangeiros; (5) jornais e artigos de jornais; (6) revistas de atualidades e seus artigos; (7) eventos nacionais e trabalhos aí apresentados; (8) eventos estrangeiros e seus trabalhos; (9) dissertações; (10) teses; (11) documentos eletrônicos; (12) outros documentos não correspondentes às categorias anteriores; (13) não identificados - documentos cuja referência não permitiu sua identificação.

- Título do periódico - no caso de artigos científicos, registrou-se o título das revistas em que foram publicados, com a identificação dos periódicos mais utilizados.

- Idioma - registrou-se o idioma dos documentos citados para indicação da preferência dos autores. Os documentos traduzidos foram categorizados como pertencentes à língua da tradução. 
- Local de publicação - analisou-se o local de publicação indicado na referências para conhecer a procedência geográfica dos documentos por países da literatura utilizada como fonte para os artigos da Intercom RBCC.

- Idade do documento - para identificar a idade dos documentos, registrou-se seu ano de publicação. No tratamento dos dados, optou-se pela análise relacionando a idade das citações aos documentos a partir dos diferentes períodos da revista.

Após a coleta, os dados foram agrupados quantitativamente por freqüência. A partir dos resultados, foram elaboradas tabelas para facilitar sua visualização e análise.

\section{RESULTADOS}

Apresentam-se os resultados do estudo de acordo com as variáveis trabalhadas antes mencionadas.

\section{Autores citados e tipo de autoria}

Dentre as 5.801 referências analisadas, 147 (2\%) não indicam o autor responsável. São referências elaboradas tendo como entrada o título dos documentos. Nas demais - 5.654 referências - há a indicação de autor, e entre estas, 265 (4,7\%) são de responsabilidade de autor entidade e as 5.389 (95,3\%), de responsabilidade de autores pessoais. Foram consideradas como referentes ao autor entidade as citações a documentos atrelados a órgãos governamentais, empresas, associações, congressos, etc. Dentre elas, ou seja, dentre as 265 citações, há documentos das mais variadas entidades, como Organização das Nações Unidas para a Educação, a Ciência e a Cultura (UNESCO) e do Governo Federal (BRASIL...). Na verdade, são 166 entidades diferentes, sem que nenhuma apresente percentual elevado em comparação às outras.

No caso das 5.389 citações de autores pessoais, em $66(1,2 \%)$ delas, há o uso da expressão et al., que indica a responsabilidade de mais de três pesquisadores. Nestes casos, o documento apresenta autoria múltipla, mas é impossível identificar o total exato de autores responsáveis e quem são eles. A falta da indicação de todos os autores foi ignorada para a obtenção da freqüência dos autores citados, sendo incluídos na contagem todos os autores cujos nomes foram indicados nas referências. Assim, nas 5.801 referências analisadas, foram detectados 3.604 diferentes autores pessoais. Considerou-se como os mais citados aqueles com 21 citações ou mais. Dentro deste critério, a Tabela 1 apresenta os nomes dos 13 autores mais citados e as respectivas freqüências de citação.

Os autores com freqüência de citação igual ou inferior a 21 foram agrupados ao final da Tabela 1. O resultado da análise revelou pequeno núcleo de autores no qual se concentram as citações. Observa-se, também, significativa 
diversidade de autores nos quais os artigos publicados na Intercom - RBCC foram embasados. O autor pessoal com maior número de citações é José Marques de Melo (professor da Universidade Metodista de São Paulo, UMESP), autor brasileiro consagrado na área de Comunicação, com 106 citações, isto é, $2,3 \%$ do total. Entre os mais citados, há diferentes nacionalidades e diferentes áreas de conhecimento, como Jurgen Habermas, pesquisador alemão dedicado a estudos de Sociologia, e Armand Mattelart, belga e estudioso dos campos da Sociologia e da Comunicação.

Tabela 1 - Freqüência dos autores mais citados

\begin{tabular}{l|c||c}
\hline \hline \multicolumn{1}{c||}{ AUTOR } & Freqüência citação & $\%$ \\
\hline \hline José Marques de Melo & 106 & 2,3 \\
Jesús Martín-Barbero & 57 & 1,2 \\
Armand Mattelart & 42 & 0,9 \\
Pierre Bourdieu & 41 & 0,9 \\
Paulo Freire & 39 & 0,9 \\
Guillermo Orozco Gómez & 30 & 0,7 \\
César Ricardo Siqueira Bolaño & 29 & 0,6 \\
Jurgen Habermas & 27 & 0,6 \\
Néstor García Canclini & 25 & 0,5 \\
Sérgio Caparelli & 23 & 0,5 \\
Roland Barthes & 22 & 0,5 \\
Muniz Sodré & 21 & 0,5 \\
Umberto Eco & 21 & 0,5 \\
Autores com freqüência de 15 a 20 citações & 12 & 4,8 \\
Autores com freqüência de 10 a 14 citações & 271 & 5,8 \\
Autores com freqüência de 6 a 9 citações & 123 & 2,7 \\
Autores com freqüência de 2 a 5 citações & 695 & 15,2 \\
Autores com freqüência de 1 citação & 2.779 & 60,9 \\
\hline \hline TOTAL & 4.363 & 100,0 \\
\hline \hline 3.604 autores & & \\
\hline \hline
\end{tabular}

Em se tratando do tipo de autoria - citações de documentos de autoria única e autoria múltipla - como resultado, observou-se que a maior parte das citações é de documentos publicados individualmente. Das 5.801 citações analisadas, 4.740 (86\%) são de trabalhos de autoria única e 649 (11\%) são de múltipla autoria. Os 3\% restantes referem-se às citações nas quais não foi possível identificar os autores. 


\section{Autocitação}

A autocitação é uma prática de citar trabalhos anteriores do autor do artigo citante, em que o autor usa trabalhos dele mesmo como fonte de informação. Dos 287 artigos analisados, identificou-se o uso da autocitação em 137 artigos. Ou seja, os autores que publicaram na Intercom - RCBB se autocitaram em $48 \%$ dos artigos publicados entre 1985 e 2008. Em 47 artigos, algumas das referências indicadas não mencionam todos os autores responsáveis pelos documentos citados, o que impossibilitou identificar se houve ou não autocitação nesses artigos. Com relação às citações, a análise revelou o uso de autocitação em 346 (6\%) das 5.801 referências. Ressalta-se, porém, que o estudo não identificou as causas da autocitação. Somente a partir de análises qualitativas cuidadosas do conteúdo dos textos, as razões de citações próprias poderiam ser indicadas.

Dos autores que fizeram uso da autocitação, identificou-se como o autor com o maior número de autocitações José Marques de Melo. Em seis artigos estudados, recorreu à autocitação 38 vezes. Além dele, dos 345 autores que publicaram seus artigos na Intercom - RBCC entre 1985 e 2008, 112 fizeram uso da autocitação (32\% dos autores). Os 15 autores com maior número de autocitações (seis ou mais) estão dispostos no Quadro 1.

\begin{tabular}{|l|c|c|}
\hline \multicolumn{1}{|c||}{ Autor } & Artigos publicados & Autocitação \\
\hline \hline José Marques de Melo & 6 & 38 \\
César Ricardo Siqueira Bolaño & 6 & 21 \\
Alain Herscovici & 3 & 14 \\
Eduardo Meditsch & 5 & 10 \\
Ronaldo Helal & 1 & 9 \\
Enrique Sanchez Ruiz & 2 & 8 \\
Guillermo Orozco Gómez & 2 & 8 \\
José Carlos Lozano & 2 & 8 \\
D. C. Robinson & 1 & 7 \\
Mário Mesquita & 3 & 7 \\
Maria Immacolata Vassalo de Lopes & 3 & 6 \\
Raúl Fuentes Navarro & 1 & 6 \\
Tereza Lúcia Halliday & 1 & 6 \\
Thomas Tufte & 2 & 6 \\
\hline
\end{tabular}

Quadro 1 - Incidência de autocitação 
Os autores identificados com o maior número de autocitações fizeram uso desta prática em todos seus artigos publicados na Intercom - RBCC, o que permite inferir que a autocitação é prática recorrente para eles na elaboração de seus textos. Na literatura que trata do processo de citação, há autores que vêem tal prática como algo justificável e outros que a consideram negativa e indutiva no que concerne à produtividade e à visibilidade da produção científica. Garfield (1979) afirma que a autocitação pode ser um recurso para o pesquisador aumentar as citações a seus trabalhos e, assim, se destacar. MacRoberts e MacRoberts (1989) listam a autocitação como um dos problemas na análise de citações, por considerarem esta prática como excessiva pelos pesquisadores. Em contrapartida, Tagliacozzo (1977) afirma que a autocitação é fundamental na elaboração de artigos científicos pois, tal como as outras formas de citar, tem como função fazer referência de um trabalho a outro, conectando diferentes estudos. Uma função da autocitação seria unir trabalhos complementares, facilitando ao leitor obter informações adicionais ao tema abordado.

Há trabalhos, como o de Pittella (1991), que relacionam a autocitação numa publicação específica. No caso da Intercom - RBCC, dos 819 artigos citados como fonte de referência em seus 287 artigos publicados, 39 foram publicados na própria Revista. São $4,7 \%$ do total de artigos de periódicos citados. A Intercom - RBCC foi a segunda revista científica mais citada, perdendo em percentuais apenas para Comunicação \& Sociedade, que aparece com cerca de $42(5,1 \%)$ artigos dentre os citados. Este resultado pode ser um indicador positivo que confirma o fato de Intercom - RBCC ser considerada publicação relevante no campo da Comunicação.

\section{Tipo de documento}

A Tabela 2 sumariza os tipos de documentos por ordem de freqüência nas citações dos artigos da Intercom - RBCC.

Tabela 2 - Freqüência por tipo de documento

\begin{tabular}{l||c||c}
\hline \hline \multicolumn{1}{c||}{ AUTOR } & Freqüência citação & $\%$ \\
\hline \hline Livros e capítulos de livros estrangeiros & 2.072 & 35,7 \\
Livros e capítulos de livros nacionais & 2.031 & 35,0 \\
Periódicos e artigos de periódicos estrangeiros & 549 & 9,5 \\
Periódicos e artigos de periódicos nacionais & 272 & 4,7 \\
Outros & 157 & 2,7 \\
Jornais e artigos de jornais & 137 & 2,4 \\
Revistas de atualidades e seus artigos & 123 & 2,1 \\
Documentos eletrônicos & 104 & 1,8 \\
Dissertações & 76 & 1,4 \\
Eventos nacionais e anais & 72 & 1,2 \\
Teses & 72 & 1,2
\end{tabular}




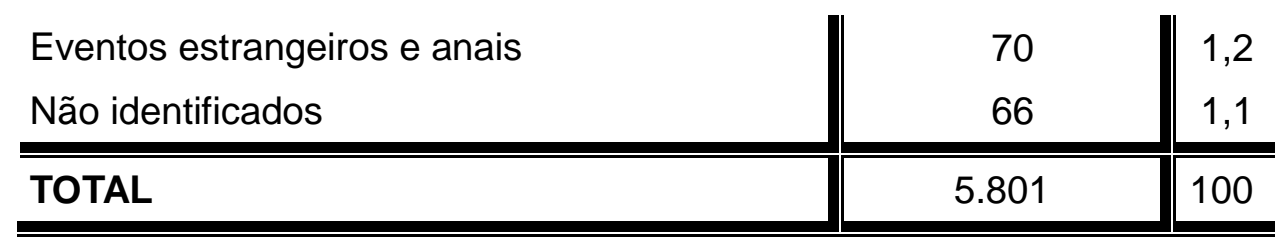

Os documentos mais utilizados são livros e capítulos de livros, com 4.103 citações, representando $70,7 \%$ do total de citações. Este percentual confirma a preferência do livro pelos profissionais de Comunicação. A este respeito, acrescenta-se que Meadows (1999) analisou a comunicação científica em diferentes áreas do conhecimento e concluiu que o livro persiste como a mais importante fonte de informação em algumas áreas, como aqui comprovado, uma vez que os livros foram cinco vezes mais utilizados do que os artigos, segundo colocado. Estes alcançam os índices de 14,2\%: 9,5\% para artigos estrangeiros e $4,7 \%$, nacionais (Tabela 2).

Das 5.801 citações dos autores da Intercom - RBCC, 157 (2,7\%) foram enquadradas na categoria - outros -, incorporando variados tipos de documentos. Entre eles: comunicações pessoais (conversas por telefone, entrevistas, depoimentos em sala de aula; documentos não publicados); textos escritos à mão; manuscritos à máquina; documentos mimeografados; notas de aula; rascunhos de trabalhos; esboços de pesquisas; correspondência; documentos audiovisuais, etc. Embora correspondam a um baixo percentual, é importante descrever os tipos de documentos para que se verifique a variedade de uso de fontes pelos autores de Comunicação. Ao mesmo tempo em que o livro, canal tradicional da comunicação científica, atinge o índice mais representativo, também há o emprego de diversos tipos de documentos, indicando que os pesquisadores recorrem a diferentes suportes. Isto é, desde que contenha informações de interesse, qualquer fonte é passível de utilização.

Os artigos de jornais e revistas de atualidades também receberam destaque entre as citações analisadas, respectivamente, $137(2,4 \%)$ e $123(2,1 \%)$ citações. Os jornais mais citados foram Folha de S. Paulo (46 citações $=33,5 \%$ do total de citações a esse tipo de documento) e Jornal do Brasil (25 citações = 18\%). A revista Veja, da Editora Abril, foi a mais citada, com oito citações (5,9\%). Foram identificados outros 62 títulos de jornais e revistas referendados apenas uma vez (Tabela 2).

As citações a documentos eletrônicos foram extraídas de diferentes fontes, como textos de sites (75 citações a textos de caráter informativo e / ou opinativo); material disponível em Compact Disc Read-Only Memory (CD-ROM), com uma citação; conteúdo de comunicações pessoais eletrônicas (informações via e-mail, também uma citação); dentre outros. Em 21 citações não foi possível identificar de que fonte foram extraídas, pois a busca por endereços eletrônicos teve como resultados sites inexistentes ou indisponíveis.

Ainda como mostra a Tabela 2, dissertações e teses não obtiveram percentual significativo: 1,3\% para dissertações (76 citações) e 1,2\% para teses (72 citações). Significativa parte dos autores citou os próprios trabalhos acadêmicos na elaboração de seus textos, o que pode indicar continuidade nos estudos anteriores ou a publicação de dissertações e teses sob a forma de 
artigos, para maior divulgação dos resultados da pesquisa. Por outro lado, as citações a documentos resultantes de eventos tiveram $2,4 \%$ do total -72 para nacionais e 70 para estrangeiros.

A elaboração incorreta de referências e a falta dos elementos essenciais para a localização posterior de documentos, contrariando a norma da ABNT NBR 6023 / 2002, torna-se prejudicial à análise de citações. No caso dos artigos da Intercom - RBCC, em 66 citações (1,1\% do total de 5.801$)$, o tipo de documento não pôde ser identificado, por falta de informações nas referências.

\section{Título do periódico}

Foram 821 citações a artigos científicos nacionais e estrangeiros num total de 337 títulos de periódicos diferentes. As freqüências estão apresentadas na Tabela 3.

Tabela 3 - Periódicos mais citados

\begin{tabular}{l|c||c||c}
\hline \multicolumn{1}{c||}{ TíTULO DE PERIÓDICO } & Freqüência citação & $\%$ & $\boldsymbol{\Sigma}$ \\
\hline \hline Comunicação \& Sociedade & 42 & 5,1 & 5,1 \\
Intercom - RBCC & 39 & 4,7 & 9,8 \\
Diálogos de La Comunicación & 33 & 4,0 & 13,8 \\
Comunicación y Cultura & 29 & 3,5 & 17,3 \\
Journal of Communication & 26 & 3,1 & 20,4 \\
Journalism Quarterly & 22 & 2,6 & 23,0 \\
Media, Culture and Society & 20 & 2,4 & 25,4 \\
Critical Studies in Mass Communication & 19 & 2,4 & 27,8 \\
European Journal of Communication & 18 & 2,1 & 29,9 \\
Telos & 18 & 2,1 & 32,0 \\
Outros 327 periódicos & 555 & 68,0 & 100 \\
\hline \hline TOTAL & 821 & 100,0 & \\
\hline \hline
\end{tabular}

Das citações a periódicos científicos, pequena parte dos títulos citados concentra a maior parte das citações realizadas a este tipo de documento, enquanto muitos dos títulos de periódicos foram citados apenas uma vez. Entre os 337 periódicos citados, 10 representam 32\% do total de 821 citações. Dentre as revistas mais citadas, duas são brasileiras e as oito restantes, estrangeiras. $O$ título que conta com o índice mais elevado de citações é o periódico brasileiro Comunicação \& Sociedade, com $42(5,1 \%)$ citações, seguido da própria revista Intercom - RBCC, com 39 (4,7\%) citações.

\section{Idioma}


A análise das citações identificou sete idiomas diferentes entre os documentos utilizados. A Tabela 4 apresenta sua distribuição. Vê-se que o português foi o idioma mais utilizado, totalizando 3.051 (53\%), ou seja, mais da metade do total das 5.801 citações analisadas. Em sua dissertação, Vanz (2004) atenta para o cuidado com que resultados como este devem ser observados. A identificação do idioma predominante não indica que os documentos utilizados foram escritos ou publicados originalmente nesse idioma. Ao comparar os resultados referentes à língua com os autores identificados como os mais citados, dentre os quais há elevado percentagem de autores estrangeiros, deduz-se que muitos dos documentos utilizados resultam de traduções brasileiras. Há, ainda, a possibilidade, ao identificar o idioma da publicação como sendo o português, que esta provenha de outras nações de língua portuguesa. O que se observa, então, é preferência por parte dos autores por publicações em português, idioma de $88,5 \%$ dos artigos publicados na Intercom - RBCC (254 artigos).

Tabela 4 - Freqüência por idioma

\begin{tabular}{l||c||c}
\hline \multicolumn{1}{c|}{ AUTOR } & Freqüência citação & $\%$ \\
\hline \hline Português & 3.051 & 53,0 \\
Inglês & 1.308 & 22,5 \\
Espanhol & 1.044 & 18,0 \\
Francês & 286 & 5,0 \\
Alemão & 59 & 1,0 \\
Italiano & 48 & 0,83 \\
Servo-croata & 3 & 0,05 \\
Não identificados & 2 & 0,03 \\
\hline \hline TOTAL & 5.801 & 100,00 \\
\hline \hline
\end{tabular}

O segundo idioma mais citado foi o inglês, presente em 1.308 documentos, o que corresponde a 22,5\%. O espanhol aparece com 1.044 (18\%) documentos e ocupa, portanto, o posto de terceiro idioma mais citado. Os demais são: francês $(5 \%)$; alemão (1\%); italiano $(0,83 \%)$ e iugoslavo $(0,05 \%)$. Não foi possível identificar o idioma de duas citações por incompletude das referências. O uso curioso de publicações em servo-croata é compreensível pela temática tratada no artigo - repercussão das produções da teledramaturgia brasileira na população da lugoslávia no ano de 1990.

\section{Local de publicação}

Ao elaborar uma referência, o autor informa a cidade na qual o documento foi publicado. Para fins deste trabalho, as cidades identificadas foram agrupadas 
por países nos quais se localizam, permitindo identificar a proveniência dos documentos citados, conforme visualizado na Tabela 5.

Foram identificadas citações de documentos publicados em 52 países diferentes. O Brasil é o país com maior número de publicações citadas: 2.799 citações a documentos brasileiros (48,25\%). Em seguida, os Estados Unidos da América (EUA) aparecem com o segundo maior número de citações, com 671 documentos, ou seja, 11,57\%. Referências sem indicação de local chegaram a 189 (3,26\%), com o adendo de que o número inicial era de 787, razão pela qual se optou por completar este dado mediante buscas na internet. Os artigos são o maior número de documentos cujas referências não informam o local de publicação, mesmo sendo este um elemento obrigatório para elaboração de sua referência.

As informações acerca do local de publicação devem ser observadas com o mesmo cuidado com que se analisam os resultados referentes ao idioma das citações. O local de publicação não necessariamente indica o local em que a obra foi escrita, podendo indicar uma tradução.

Tabela 5 - Freqüência por local de publicação

\begin{tabular}{l||c||c}
\hline \hline \multicolumn{1}{c||}{ País de Publicação } & $\begin{array}{c}\text { Documentos } \\
\text { (N) }\end{array}$ & $\%$ \\
\hline \hline Brasil & 2.799 & 48,25 \\
Estados Unidos da América & 671 & 11,57 \\
Inglaterra & 363 & 6,26 \\
México & 325 & 5,60 \\
França & 280 & 4,83 \\
Espanha & 279 & 4,81 \\
Portugal & 223 & 3,84 \\
Argentina & 97 & 1,67 \\
Alemanha & 65 & 1,12 \\
Peru & 65 & 1,12 \\
Itália & 57 & 0,98 \\
Chile & 49 & 0,84 \\
Venezuela & 49 & 0,84 \\
Equador & 40 & 0,69 \\
Colômbia & 39 & 0,67 \\
Rússia & 36 & 0,62 \\
Canadá & 27 & 0,47 \\
Cuba & & 0,40 \\
& &
\end{tabular}




\begin{tabular}{l||r||c} 
Países (menos 20 citações = 18) & 109 & 1,87 \\
Países (uma citação =16) & 16 & 0,32 \\
Não identificados & 189 & 3,26 \\
\hline \hline TOTAL & 5.801 & 100 \\
\hline \hline
\end{tabular}

\section{Idade dos documentos}

A idade das citações foi analisada a partir do ano de publicação dos documentos citados e agrupados por período de publicação dos artigos que as citam. Silva e Bianchi (2001, p. 7) afirmam que "o ritmo de envelhecimento da bibliografia referenciada nas diferentes áreas do saber varia em função da velocidade do progresso científico de cada uma, o que determina a rapidez com que os trabalhos são citados". O Quadro 2 sintetiza os resultados obtidos.

\begin{tabular}{|c|c|c|c|c|c|c|c|c|}
\hline \multirow{2}{*}{$\begin{array}{l}\text { Período de } \\
\text { publicação }\end{array}$} & \multirow{2}{*}{$\begin{array}{l}\text { Total de } \\
\text { citações }\end{array}$} & \multicolumn{7}{|c|}{ ANO DAS CITAÇÕES } \\
\hline & & \begin{tabular}{|c} 
Antes de \\
1985
\end{tabular} & $\begin{array}{c}1985 \mathrm{a} \\
1989\end{array}$ & $\begin{array}{c}1990 \mathrm{a} \\
1994\end{array}$ & $\begin{array}{c}1995 \mathrm{a} \\
1999\end{array}$ & $\begin{array}{l}2000 a \\
2004\end{array}$ & $\begin{array}{c}2005 a \\
2008\end{array}$ & s.d. \\
\hline $1985-1989$ & 338 & 288 & 44 & - & - & - & - & 6 \\
\hline $1990-1994$ & 1.469 & 568 & 500 & 369 & - & - & - & 32 \\
\hline $1995-1999$ & 1.290 & 393 & 257 & 408 & 209 & - & - & 23 \\
\hline $2000-2004$ & 1.282 & 316 & 139 & 232 & 403 & 172 & - & 20 \\
\hline $2005-2008$ & 1.422 & 199 & 104 & 198 & 275 & 436 & 156 & 54 \\
\hline TOTAL & 5.801 & 1.764 & 1.044 & 1.207 & 887 & 608 & 156 & 135 \\
\hline
\end{tabular}

Quadro 2 - Idade dos documentos citados e ano de publicação dos artigos onde estão citados

A análise por período das publicações dos artigos indica que o maior número de documentos citados (1.764) foi publicado antes de 1985, independentemente do ano de publicação. O Quadro 2 mostra ainda que, com o passar do tempo, as citações e o uso de textos menos recentes aumentaram. Isto indica que fontes publicadas há mais tempo continuam sendo utilizadas por pesquisadores em Comunicação. Também pode ser indício de que as obras publicadas demoram certo tempo para serem incorporadas à literatura da área e, por conseguinte, os autores só começam a citá-las com o passar dos anos.

A leitura do referido quadro, tanto horizontal quanto verticalmente, não permite observar qualquer outra tendência em relação à idade das citações, independentemente da data dos artigos publicados. Ademais, esclarece-se que a abreviatura s.d. (sem data) foi adotada para designar tanto os documentos sem informações sobre 0 ano de publicação quanto as referências de citações a documentos eletrônicos que indicavam apenas a data de acesso, não remetendo 
ao ano real de edição. A não indicação da data de publicação impossibilita conhecer a atualidade do documento citado em relação ao documento citante. No período de 1985 a 2008, isto ocorreu apenas em 135 (2,5\%) casos.

\section{CONSIDERAÇÕES FINAIS}

A intenção deste trabalho foi contribuir com os estudos referentes à produção científica da área de Comunicação no Brasil, no que concerne às características das citações utilizadas pelos autores de artigos publicados na revista Intercom - RBCC, entre 1985 e 2008. Os dados apresentados refletem o comportamento de citação de parcela significativa de pesquisadores da área.

Os 287 artigos analisados apresentaram 5.801 citações que foram objeto de estudo. Em relação às características das citações, identificou-se que em $93 \%$ (5.389), há indicação de responsabilidade pela obra de um autor pessoal. Foram citados 3.604 diferentes autores pessoais, sendo José Marques de Melo o autor com maior número de citações: 106 citações ou 2,3\% do total. A autocitação apareceu em 137 artigos e Marques de Melo foi também o autor com maior número de autocitações (38).

O estudo constatou que o tipo de documento mais citado foi o livro e o capítulo de livro, com $70,7 \%$ do total de citações. Este dado corrobora a afirmação de que tais fontes são preferidas nas Ciências Humanas e Sociais (MEADOWS, 1999) e também em Comunicação, como constatam o estudo de citações em dissertações feito por Vanz (2004). Os artigos de periódicos, embora representem apenas $14,2 \%$ das citações, referenciam 337 títulos diferentes, nacionais e estrangeiros. Os dois títulos mais citados são nacionais, entre eles a própria revista Intercom - RBCC (39 citações $=4,7 \%$ ), que vem após Comunicação \& Sociedade, com 42 (5,1\%) menções.

Dentre os sete idiomas identificados nas referências, o português foi o mais utilizado, alcançando 53\% das citações (3.051), ou seja, mais da metade do total das 5.801 citações analisadas. A seguir, vieram inglês $(22,50 \%)$ e espanhol (18\%). Reitera-se que a identificação do idioma não indica que os documentos foram escritos ou publicados originalmente nos idiomas identificados.

Quanto aos locais de publicação, as 2.799 citações a publicações brasileiras correspondem a quase a metade do total de citações, chegando a $48,25 \%$. Os EUA apareceram com o segundo maior número de citações, quer dizer, é o país onde foram editados 671 (11,57\%) documentos citados.

Sobre a idade dos textos, o maior percentual de documentos citados foi publicado antes dos anos 90 . Análise comparativa entre ano do artigo analisado e ano das referências citadas demonstrou que, com o passar do tempo, aumentaram as citações a fontes menos recentes.

Mesmo sendo um estudo que exige coleta de dados muito prolongada (foram necessários cerca de três meses) e, por conseguinte, bastante esforço e dedicação, é importante que estudos semelhantes sejam desenvolvidos. Reafirma-se sua importância como forma de acompanhar o avanço de uma área e de detectar as tendências informacionais de seus pesquisadores. 
Sobre a metodologia escolhida, o software Excel e suas ferramentas foram satisfatórios e atenderam às necessidades do estudo. Verificou-se a possibilidade de organizar de diferentes formas as variáveis analisadas com instrumentos eficientes para obtenção de gráficos e de tabelas em adequação com as análises pretendidas.

Durante a coleta, registraram-se diversos problemas na elaboração das referências, principalmente com relação à incompletude de informações essenciais. Isto demonstra falha dos pesquisadores em seguir as normas de elaboração de referências. Identificou-se o total de 1.058 referências incompletas ou elaboradas de modo incompreensível, o que conduziu à alternativa de revisão dos campos incompletos e / ou incompreensíveis mediante buscas na internet. $O$ resultado foi a redução para 330 referências inconsistentes. As referências elaboradas de modo incompleto ou erroneamente dificultaram a identificação das características pretendidas.

As informações sobre local e ano de publicação foram as que apresentaram maiores problemas, embora eles tenham ocorrido para todas as variáveis. A falta de padronização dos nomes dos autores citados, escritos de diferentes formas ou, em muitos casos, com erros na grafia, foi outro elemento dificultador. Atenta-se para a necessidade da correta elaboração das referências, tanto para fins de novos estudos bibliométricos quanto para padronização dos artigos da área. A referenciação completa permite não só a identificação correta de seus componentes, mas também que outros pesquisadores fundamentem seus estudos nas mesmas fontes.

Além do mais, vale afirmar que os estudos das citações da revista Intercom - RBCC identificaram peculiaridades sobre o uso de fontes de informação por pesquisadores da Comunicação. Estes se valem de materiais não científicos, mas considerados essenciais para o avanço de suas pesquisas, como revistas de atualidades e jornais. Em outras palavras, os dados obtidos contribuíram para entendimento do processo de uso de fontes de informação pelos pesquisadores em Comunicação, mas também podem ser úteis para estabelecimento de políticas de desenvolvimento de coleções em unidades de informação destinadas a essa área do conhecimento, pois permitem identificar fontes preferidas e características das fontes.

\section{REFERÊNCIAS}

ARAÚJO, C. A. Bibliometria: evolução histórica e questões atuais. Em Questão, Porto Alegre, v. 12, n. 1, p. 11-32, jan. / jun. 2006.

ASSOCIAÇÃO BRASILEIRA DE NORMAS TÉCNICAS (ABNT). NBR 6022: Informação e Documentação. Artigo em publicação periódica científica impressa. Apresentação. Rio de Janeiro, 2003. Janeiro, 2002.

NBR 6023: informação e Documentação: referências, elaboração. Rio de

GARFIELD, E.. Is citation analysis a legitime evaluation tool? Scientometrics, Budapest, v. 1 , n. 4, p. 359-375, 1979. 
LEITE, E. O. A monografia jurídica. 5. ed. rev. atual. e ampl. São Paulo: Revista dos Tribunais, 2001.

LOPES PIÑERO, J. M. El análisis estatístico y sociométrico de la literatura científica. Valencia: Faculdad de Medicina, 1972.

MACIAS-CHAPULA, C. A. O papel da informetria e da cienciometria e sua perspectiva nacional e internacional. Ciência da Informação, Brasília, DF, v. 27, n. 2, p. 134-140, maio / ago. 1998.

MACROBERTS, M. H.; MACROBERTS, B. R. Problems of citation analysis: a critical review. Journal of the American Society for Information Science and Technology, Maryland, v. 40, n. 5, p. 342-349, 1989.

MEADOWS, A. J. A comunicação científica. Brasília, DF: Briquet Lemos Livros,1999.

NORONHA, D. P.; FERREIRA, S. M. S. P. Índices de citação. In: CAMPELLO, B. S.; CÉNDON, B. V.; KREMER, J. M. (Org.). Fontes de informação para pesquisadores e profissionais. Belo Horizonte: UFMG, 2003. p. 249-262

PITTELLA, M. C. Análise de citação dos periódicos brasileiros de Biblioteconomia 1972 1982. Revista da Escola de Biblioteconomia da UFMG, Belo Horizonte, v. 20, n. 2, p. 191217, jul. / dez. 1991.

SILVA, J. A. da; BIANCHI, M. de L. P. Cientometria: a métrica da ciência. Paideia, Ribeirão Preto, v. 11, n. 21, p. 5-10, 2001.

TAGLIACOZZO, R. Self-citations in scientific literature. Journal of Documentation, London, v. 33, n. 4, p. 251-256, 1977.

VANZ, Samile A. S. A produção discente em Comunicação: análise das citações das dissertações defendidas nos Programas de Pós-Graduação do RGS. 2004. Dissertação (Mestrado em Comunicação e Informação) - Faculdade de Biblioteconomia e Comunicação, Universidade Federal do Rio Grande do Sul, 2004.

ZIMAN, J. Conhecimento público. Belo Horizonte: Itatiaia, 1979.

\section{Title}

Citation analysis of articles in the journal Intercom - Revista Brasileira de Ciências da Comunicação (1985-2008).

\section{Abstract}

This study investigates the scientific literature in Communication through the analysis of Intercom - Revista Brasileira de Ciências da Comunicação, one of the most important and oldest scientific publications in the area, still in activity. Through the use of bibliometric citations analysis, 287 articles published between 1985 and 2008 are analyzed. It investigates the citation process and identifies characteristics of the documents used as sources of reference for published articles. To identify the documents cited, the following variables are studied: cited authors; type of authorship; self-citation; document type; journal title; language; place of publication; and age. The analysis of 5.801 references 
reveals that: 3.604 different authors were cited, among them José Marques de Melo, Jesús Martín-Barbero, Armand Mattelart, Pierre Bordieu, Paulo Freire, Guillermo Orozco Gómez, César Ricardo Siqueira Bolaño, Jurgen Habermas, Néstor García Canclini e Sérgio Caparelli are the most cited authors. The self-citation occurs in 137 articles, totaling $6 \%$ of the references (346 citations). Books and books chapters were the most cited documents (70.7\%). Among 337 journal titles cited the ten most mentioned are: Comunicação \& Sociedade; Intercom - RBCC; Diálogos de La Comunicación; Comunicación y Cultura; Journal of Communication; Journalism Quarterly; Media, Culture and Society; Critical Studies in Mass Communication; European Journal of Communication; e Telos. Portuguese is the language of $53 \%$ of the citations, followed by English and Spanish. Most of the documents cited (48.2\%) were published in Brazil and before 1985, regardless of the articles publication year. The study shows the citation behavior of the Communication community of researchers.

\section{Keywords}

Bibliometrics. Citation Analyses. Communication Science.

\section{Título}

Análisis de citas de artículos en Intercom - Revista Brasileira de Ciências da Comunicação (1985-2008).

\section{Resumen}

Estudia la producción científica en Ciencias de la Comunicación a través del análisis de la Intercom - Revista Brasileira de Ciências da Comunicação (RBCC), la primera publicada por una sociedad científica y la más antigua en el área aún activa. A través de la técnica bibliométrica de análisis de citaciones, se analizan los 287 artículos publicados entre 1985 y 2008. De los documentos citados, se estudian las siguientes variables: autores citados; tipo de autoría; autocitación; tipo de documento; título de la revista; idioma; localidad de publicación; la antigüedad del documento. El análisis de las 5.801 referencias revela que fueron citados 3.604 diferentes autores y entre estos, están como los más citados: José Marques de Melo, Jesús Martín-Barbero, Armand Mattelart, Pierre Bordieu, Paulo Freire, Guillermo Orozco Gómez, César Ricardo Siqueira Bolaño, Jurgen Habermas, Néstor García Canclini e Sérgio Caparelli. La autocitación ocurre en 137 artículos, totalizando el 6\% del total de las citaciones (346 autocitaciones). Libro y capítulo de libro son los tipos de documento más citados (70,7\%). Entre los 337 títulos de revistas citadas, las 10 con mayor porcentaje de citaciones son: Comunicação \& Sociedade; Intercom - RBCC; Diálogos de La Comunicación; Comunicación y Cultura; Journal of Communication; Journalism Quarterly; Media, Culture and Society; Critical Studies in Mass Communication; European Journal of Communication; e Telos. El portugués es el idioma del $53 \%$ de las citaciones, seguido del inglés y español. La mayor parte de los documentos citados $(48,2 \%)$ fue publicada en Brasil y el mayor porcentaje de citaciones corresponde a documentos publicados antes de 1985, independientemente del año de publicación del artículo. El estudio revela el comportamiento de citaciones de la comunidad científica de Comunicación que se publica en Intercom - RBCC.

\section{Palabras clave}

Bibliometría. Análisis de Citaciones. Ciencias de la Comunicación.

Recebido em: 11/08/2010

Aceito em: 28/11/2010 